Bond University

Research Repository

\title{
Schizotypal personality models
}

Green, Melissa; Boyle, Gregory; Raine, Adrian

Published in:

The Sage handbook of personality theory and assessment

DOI:

10.4135/9781849200462.n19

Licence:

Other

Link to output in Bond University research repository.

Recommended citation(APA):

Green, M., Boyle, G., \& Raine, A. (2008). Schizotypal personality models. In G. J. Boyle, G. Matthews, \& D. H. Saklofske (Eds.), The Sage handbook of personality theory and assessment: Vol. 1 Personality theories and models (pp. 399-419). SAGE Publications Ltd. https://doi.org/10.4135/9781849200462.n19

\section{General rights}

Copyright and moral rights for the publications made accessible in the public portal are retained by the authors and/or other copyright owners and it is a condition of accessing publications that users recognise and abide by the legal requirements associated with these rights.

For more information, or if you believe that this document breaches copyright, please contact the Bond University research repository coordinator. 


\section{Bond University}

\section{ePublications@bond}

Humanities \& Social Sciences papers

Faculty of Humanities and Social Sciences

$1-1-2008$

\section{Schizotypal personality models}

Melissa J. Green

Adrian Raine

Gregory J. Boyle

Bond University, Gregory_Boyle@bond.edu.au

Follow this and additional works at: http://epublications.bond.edu.au/hss_pubs

Part of the Personality and Social Contexts Commons

\section{Recommended Citation}

Green, Melissa J.; Raine, Adrian; and Boyle, Gregory J., "Schizotypal personality models" (2008). Humanities \& Social Sciences papers. Paper 296.

http://epublications.bond.edu.au/hss_pubs/296

This Book Chapter is brought to you by the Faculty of Humanities and Social Sciences at ePublications@bond. It has been accepted for inclusion in Humanities \& Social Sciences papers by an authorized administrator of ePublications@bond. For more information, please contact Bond University's Repository Coordinator. 
Word count: 11,255

\title{
Schizotypal Personality Models
}

\author{
Melissa J. Green ${ }^{1}$ \\ School of Psychiatry, University of New South Wales \\ \& Black Dog Institute, Prince of Wales Hospital, Randwick. \\ Gregory J. Boyle \\ Department of Psychology, Bond University \\ \& Department of Psychiatry, University of Queensland \\ and \\ Adrian Raine \\ Department of Psychology, University of Southern California \\ \& Departments of Criminology and Psychiatry, University of Pennsylvania
} ${ }^{1}$ Address all correspondence to Melissa J. Green, Ph.D., School of Psychiatry, University of New South
Wales, Black Dog Institute Building, Hospital Road, Randwick, NSW, 2031, Australia. 
'Schizotypy' is a multidimensional construct referring to a range of biologically determined personality factors, reflected in cognitive style and perceptual experiences that manifest as subclinical levels of psychotic-like behaviours in otherwise psychologically healthy individuals (Claridge, 1985). Recent epidemiological studies provide support for the continuity of psychotic experience in the general population (see Hanssen et al., 2005; Johns \& van Os, 2001; van Os et al., 2000, 2001), observed as oddities of belief, behaviour, eccentricities, idiosyncratic speech, peculiar ideas, and social awkwardness or aversion (Siever et al., 1993). Whilst these schizotypal personality features may represent a dimensional susceptibility to clinically psychotic behaviour, the precise relationship of schizotypy with clinical disorders such as schizophrenia and schizotypal personality disorder (SPD) is a matter of continuing debate. This chapter will provide an outline of the historical development of the schizotypy construct, highlighting subtle theoretical differences in its conceptualisation, and related issues of measurement, factor structure, and the association with other dimensions of personality. The development of schizotypal personality models and their relationship with clinical disorders will be discussed in light of several decades of research in neurocognition, psychophysiology, and psychosocial risk factors, from which the current conceptualisation of schizotypy within a biosocial neurodevelopmental framework has emerged.

Empirical evidence for the continuity of psychosis has emerged from research into the genetics (Gottesman \& Shields, 1972), psychophysiology (Raine et al., 1995), and neuropsychology of schizophrenia (Rosa et al., 2000), supporting the idea that multiple genes contribute to the inheritance of personality traits that define one's psychotic disposition (Claridge, 1985). This view acknowledges the potential interplay between the proposed genetic predisposition to schizophrenia (diathesis) and the combined effects of 
certain life experiences (stress) in accounting for an individual's decompensation to clinical schizophrenia (cf. Grossarth-Maticek et al., 1994). The involvement of both genetic and environmental factors has been inferred from the less than perfect monozygotic concordance rate of approximately 50\% - 60\%, for the development of schizophrenia (Kender \& Diehl, 1993), this being over 50 times greater than the lifetime morbidity risk of 1\% (Hamilton, 1984; Warner, 1985), and four to five times greater than the same-sex dizygotic concordance (Gottesman \& Shields, 1972; Lytton et al., 1988).

\section{Theoretical Models of Schizotypy}

Models of schizotypal personality have developed in recent decades in line with a conceptual shift in thinking about psychosis from a continuum perspective (cf. Claridge, 1997, 1985; Eysenck \& Eysenck, 1977; Meehl, 1962, 1990; Ortet et al., 1999; Raine, 2006; Raine et al., 1995). Within this framework, there have been three major theoretical models of schizotypal personality: the quasi-dimensional (or disease) model (Meehl, 1962; Rado, 1953) which places the schizotypy-schizophrenia continuum within the realm of illness; the totally dimensional view (Eysenck, 1947; Eysenck \& Eysenck, 1977), based in personality theory, which makes no distinction between enduring personality traits and signs of abnormality; and the fully dimensional model (Claridge, 1997), based also in personality theory, but which proposes that some discontinuity of function must demarcate the line between psychological health and abnormality or disease. It is important to distinguish the tenants of each of these models at the outset.

The quasi-dimensional model endorsed by Meehl (1962, 1990; following initial formulations by Rado, 1953), represents a categorical approach to schizophrenic aetiology by presupposing a qualitative distinction between signs of health and those of disorder, 
consistent with orthodox psychiatry. Within this neurodevelopmental model, schizotypy refers to a typology of behaviours expressed by a discrete class of individuals with a common defective genotype (Meehl, 1962, 1989, 1990). According to this view, schizotypal personality traits arise due to the presence of the genetically determined integrative neural defect (termed hypokrisia) that is hypothesized to affect neural functioning throughout the brain. The effects of hypokrisia on the brain are characterised by an "insufficiency of separation, differentiation, or discrimination" in neural transmission that amounts to a ubiquitous anomaly of synaptic control within the central nervous system (CNS), termed schizotaxia, and this brain organization is argued to represent the genetically determined predisposition to schizophrenia (Meehl, 1990). The essential element of the integrative neural defect that produces the schizotaxic nervous system (i.e., neuronal “slippage”) is thus conceived as more than a simple inhibitory deficit or basic sensory abnormality, and can be seen to map directly onto schizophrenic symptomatology such as associative loosening and cognitive-affective dysregulation. Indeed, modern incarnations of these ideas are evident in contemporary models of schizophrenia such as those proposing aberrant neuronal connectivity under the guise of new terminology, such as cognitive dysmetria (Andreasen et al., 1998; Dolan et al., 1999; Friston, 1999a).

Further elaboration of Meehl's model (1990) predicts that the transition from schizotaxia to schizophrenia should involve the interaction of other factors such as environmental influences (e.g., social learning experiences) and a range of genetically determined personality dimensions (independent of schizotaxia) referred to as polygenic potentiators. A potentiator was defined as any genetic factor which, given the presence of the schizogene, had the potential to raise the probability of schizotypal decompensation. Potentiators thus included personality dimensions of social introversion, anxiety proneness, 
aggressivity, anhedonia (among others), that did not literally modify the expression of the putative schizogene, but instead interacted with the established schizotypal personality organisation and the social environment to either facilitate or depotentiate the development of overt psychotic symptoms. The interaction between schizotaxia and social learning experiences was therefore also hypothesized to contribute directly to the development and expression of schizotypal personality organization. The term "schizotype” was used by Meehl to denote an individual displaying schizotypal behaviours or experiences as a result of this interplay.

In review, Meehl's concept of schizotypy refers to the personality organisation resulting from the interaction of an inherited schizotaxic brain with other polygenetically determined personality traits and random environmental influences, and ultimately represents the phenotypic expression of vulnerability to schizophrenia. Meehl's model represents a quasidimensional account because of the clear demarcation proposed to exist between the healthy and schizotaxic brain: that is, the abnormal brain state (schizotaxia) is taken as a reference point, and dimensions of the spectrum of schizophrenia-like (schizotypal) behaviours are construed as degrees of expression of disorder, with the ultimate end-point of decompensation being schizophrenia. While this model does not imply that all schizotypes will develop schizophrenia (a common misperception of Meehl's theoretical views - see Lenzenweger, 2006), Meehl did contend that nearly all individuals with a schizotaxic brain would develop schizotypal personality on the basis of social learning regimes. Regardless of the level of decompensation, the descriptors of dysfunction along the schizotaxia-schizotypy-schizophrenia continuum consisted of overt signs of abnormality, ranging from subclinical levels of deviance detectable on laboratory measures (e.g., psychometric or neurocognitive measures) to full-blown schizophrenia or other 
schizotypic psychopathology (e.g., schizotypal or paranoid personality disorder). As such, this quasi-dimensional model places the continuity of function within the schizophrenia spectrum completely in the abnormal/illness domain. On this view, outstanding issues for debate include those of nosological relevance, such as how to differentiate factors contributing to the development of schizophrenia versus SPD.

In contrast to Meehl's quasi-dimensional model of schizotypy, both the totally- and fullydimensional models endorsed by Eysenck $(1947,1977)$ and Claridge $(1985,1997)$ respectively, place the starting point of schizotypal continuity within the normal/healthy domain of functioning. Historically these models emerged from studies of personality and temperament within experimental psychology. As an opponent of the disease concept in psychiatry, Eysenck’s (1960) influential personality theory saw the placement of psychotic illness at the extreme end of a continuously variable personality dimension, couched within naturally occurring variation in CNS functioning. This proposed biological origin of personality dimensions was historically derived from the Pavlovian concept of "nervous types”, wherein variations in personality or temperament are seen to reflect the underlying capacity of the CNS to endure or tolerate the action of very strong stimulation, reflecting a combination of weakness or strength of excitatory and inhibitory capacity of the CNS (Pavlov, 1928; cf. Boyle, 1992). At the time, Eysenck’s (1960) proposal of an inextricable connection between normal and abnormal personality along with the assumption of biological causation dissected many issues within the ongoing debate between psychiatry and the sociologically minded anti-psychiatry movement. The development of the biological personality paradigm burgeoned a new perspective on mental illness that neither accepted the orthodox organic view nor the exclusively sociological, non-biological view, but instead attempted an integration of both. 
As such, the fully-dimensional model of schizotypy endorsed by Claridge $(1985,1997)$ took the normality of health, or more precisely, normal variation in personality, as the starting point of the schizotypal spectrum (Claridge \& Beech, 1995). According to Claridge (1985), schizotypy denotes a range of enduring personality traits, reflected in cognitive style and perceptual experiences, arising from a combination of polygenetic and environmental determinants, which are normally distributed within the general population. Claridge's model of schizotypy drew parallels between psychiatric illness and systemic diseases of the body, using the example of hypertension (in which sustained high blood pressure brings about irreversible signs of disease evidenced in multiple physiological systems), as a template for understanding the origins of mental illness. Claridge (1985) argued that both systemic and mental diseases could be seen to arise from a breakdown in the otherwise normal functioning of a biological system, rather than an affliction imposed on the body. A second shared quality could be seen in the continuity between adaptive and maladaptive functioning of the system, given arbitrary cut-off points for determining abnormal functioning. Thirdly, both systemic and mental diseases may have multiple causes; in the case of hypertension, a number of environmental factors such as smoking, lack of exercise, diet, obesity and stress, may contribute to aberrant and sustained high blood pressure. Similarly, a variety of factors including genetic, psychosocial, and adverse life experiences may contribute to psychological ill health. In summary, Claridge (1985, p. 11) argued that "the genetically influenced variations in brain organization which underlie temperamental and personality differences...can be construed as dispositions to varying forms of mental disorder; and that the emergence of such disorder is, in essence, a transformation of these biological dispositions into signs of illness”... "It is only at the extremes that the disease ‘entities’ of psychiatry become clearly definable”. 
An important distinction between the fully-dimensional model proposed by Claridge (1985/1997) and Eysenck’s 'totally-dimensional' model is that the former proposes a distinct boundary between health and illness along the schizotypal-schizophrenia continuum, where signs of discontinuity of function are used to denote disorder. For Claridge, schizotypal traits comprise dual properties insofar as they represent adaptive variation in personality but also comprise the potential for maladaptive psychological functioning. Consistent with Meehl (1990), Claridge contended that the transformation from schizotypy to clinically defined schizophrenia may occur for a variety of reasons, including a relative weakness of the predisposing personality factors in question, the degree to which modifying experiences throughout life have afforded protection against severe disorder, and/or an absence of external triggers in the individual's life experiences. The fully-dimensional model of schizotypy can therefore be seen to encompass both the quasiand totally-dimensional accounts described above: the continuity of schizotypal behaviours and experiences are regarded as inherent in normal personality variation and are recognised as representing only a predisposition to disorder within a spectrum of schizophrenic psychiatric illness (see DSM-IV criteria for schizophrenia; SPD; schizoaffective disorder; and paranoid personality disorder), while the decompensation to disorder must involve a disintegration of functioning into the abnormal domain.

Despite these subtle theoretical distinctions, considerable effort has been directed towards the development of psychometric indices of schizotypy and the investigation of psychophysiological correlates of schizotypal personality organization. Variability in the expression of schizotypy may reflect the severity of decompensation toward psychosis, and/or the type of schizotypal and other potentially protective personality traits present on the endophenotype. Schizotypal personality may thus manifest in mild thought disorder, 
excessive social anxiety, or in aberrant perceptual experiences that may not be objectively observable. In other cases, manifestations of schizotypy may be detectable only via laboratory measures of psychophysiological responding (such as eye-tracking dysfunction, sustained attention deficits, psychomotor impairment).

\section{Psychometric measurement of schizotypy}

The measurement of schizotypal traits and the investigation of their psychophysiological correlates has become an increasingly popular strategy for research into the aetiology of schizophrenia spectrum disorders. This approach removes all potential confounds due to illness factors (such as the long-term impact of multiple hospitalisations and/or the use of psychotropic medications), and may enable detection of individuals “at risk” for developing psychosis, thereby allowing possible preventative action to be taken (see Boyle, 1998a,b; Claridge, 1994, 1997; Claridge \& Beech, 1996; Claridge et al., 1996; Lenzenweger, 1994; Raine et al., 1995; Tyrka et al., 1995; Vollema \& van den Bosch, 1995). Whilst the medical model of schizophrenia has not been entirely jettisoned by this endeavour, increasing focus upon the psychotic continuum may reflect scepticism regarding the past century of research that has not yet elucidated the causal factors of schizophrenia as a categorical entity.

There are two strategies for assessing schizotypy in the general population: one 'high risk' approach involves the study of biological relatives of individuals with schizophrenia, since schizotypal traits should be found more commonly among those with a diagnosed schizophrenic as a blood relative (Claridge, 1984); another approach involves the investigation of members of the general population who score highly on psychometric indices of schizotypy, regardless of familial history of illness. Individuals reporting high levels of schizotypy have shown similar patterns of performance as schizophrenia patients 
in several cognitive, psychophysiological, and neuropsychological domains (Claridge, 1997; Raine et al., 1995). These findings are reviewed in a later section.

Several attempts have been made to measure schizotypal personality traits by administering self-report scales to samples drawn from the general adult population. The content and style of psychometric measures of schizotypal personality traits has varied according to the investigators' aims and theoretical standing. The earliest schizotypy scales focused on the measurement of vulnerability for specific symptoms of schizophrenia, including perceptual aberration (Chapman et al., 1978), magical ideation (Eckblad \& Chapman, 1983), physical and social anhedonia (Chapman et al., 1976), hypomanic personality traits (Eckblad \& Chapman, 1986), predisposition to hallucination (Launay \& Slade, 1981), and more recently for delusions (Peters et al.,1999), paranoia (Rawlings \& Freeman, 1996) and schizotypal cognitions (Rust, 1988). Other psychometric scales have been formulated on the basis of psychiatric classification systems for ‘schizotypal personality’ (Raine, 1991) and/or 'borderline personality’ disorders (Claridge \& Broks, 1984), or by assuming the existence of fundamental components such as the asocial element of 'psychoticism' proposed by Eysenck and Eysenck (1977). In contrast, the recent development of psychometric scales tapping the general schizotypy construct has been based upon the empirically observed factor structure of schizotypal traits (Mason \& Claridge, 2006; Mason et al., 1995; 2005; Rawlings \& MacFarlane, 1994).

Factor analytic studies have supported the existence of up to four psychometrically distinct schizotypal dimensions depending on the range and content of the scales included in the analyses of schizotypal personality traits in the general population (Bentall et al., 1989; Boyle, 2003, 2004b, 2006; Boyle \& Baxter, 2004a; Chen et al., 1997; Claridge et al., 1996; 
Fossati et al., 2003; Hewitt \& Claridge, 1989; Kelley \& Coursey, 1992; Kendler \& Hewitt, 1992; Mason et al., 1997; Montag \& Levin, 1992; Raine \& Allbutt, 1989; Raine et al., 1994; Venables \& Rector, 2000). Evidence of distinct schizotypal trait dimensions also comes from the biological relatives of schizophrenic patients (Calkins et al., 2004), clinical patients with schizophrenia (Arndt et al., 1991; Bentall et al., 1989; Bergman et al., 2000; Liddle, 1987; Mason, 1995; Peralta et al., 1997; Thompson \& Meltzer, 1993) and schizotypal personality disorder (Axelrod et al., 2001; Battaglia et al., 1997). The threefactor version of schizotypal trait dimensions parallels Liddle's three 'syndromes' of schizophrenia represented by the factors of 'reality distortion', 'disorganisation', and 'psychomotor poverty'. Furthermore, this factor structure appears to be invariant to gender, ethnicity, religion and social background (Reynolds et al., 2000), and may be seen to support the fully-dimensional model of schizotypy (Goulding, 2004).

Possibly the most comprehensive measure of schizotypal personality - the Combined Schizotypal Traits Questionnaire (CSTQ) - was constructed by Claridge et al. (1996) to comprise 18 self-report scales (altogether there were 420 dichotomously scored items) including the following:

- Schizotypy Questionnaire (STQ) - STA \& STB scales (Claridge \& Broks, 1984)

- Physical (PhA) \& Social Anhedonia (SoA) scales (Chapman et al., 1976)

- Perceptual Aberration (PAb) scale (Chapman et al., 1980)

- Magical Ideation (MgI) scale (Eckblad \& Chapman, 1983)

- Hypomanic Personality (HoP) scale (Eckblad \& Chapman, 1986)

- Launay-Slade Hallucination scale (Launay \& Slade, 1981)

- Schizophrenism (NP) scale (Nielsen \& Petersen (1976)

- MMPI Schizoidia scale (Golden \& Meehl, 1979)

- Delusions Symptoms (Grandeur; Disintegration; Persecution; Contrition)--(Foulds \& Bedford, 1975)

- E, N, P, L (EPQ) scales (Eysenck \& Eysenck, 1975) 
Using a large sample of 1,095 individuals, an iterative maximum-likelihood exploratory factor analysis of the CSTQ scale intercorrelations (excluding the Foulds and Bedford (1975) delusional scales which were markedly skewed) was undertaken together with oblique simple-structure rotation (Claridge et al., 1996). Four schizotypal factors were reported, reflecting 'perceptual aberration', ‘cognitive disorganization', 'introverted anhedonia', and 'impulsive non-conformity'. The first factor was represented by aberrant perceptual experiences and paranormal beliefs and cognition (including magical thinking, ideas of reference, paranoid ideation), thus reflecting subclinical forms of psychotic delusions and hallucinations. The second factor referred to subclinical forms of cognitive disorganization, reflected in thought-blocking, disorganized speech, attentional difficulties (e.g., distractibility), as well as mild forms of worry and social anxiety. The third factor tapped subclinical experiences of social withdrawal and the inability to experience pleasure. Finally, the fourth factor referred to subclinical asocial behaviours such as drug-taking, violence, and deception, more typically associated with antisocial or psychopathic personality disorders. The Claridge et al. four-factor solution attained a \pm .10 hyperplane count (i.e., the proportion of factor loadings $\leq .10$ in magnitude) of $35.7 \%$, suggesting only moderate approximation to simple structure criteria (cf. Cattell, 1978; Child, 1990).

Subsequently, Boyle (1998) reanalysed the CSTQ data, using a slightly smaller, but more refined sample $(\mathrm{N}=1021)$, this time including the Foulds and Bedford (1975) delusional scales (following application of a square root transformation to reduce their skewness). An iterative maximum-likelihood procedure was undertaken, with factor number estimated via the Scree test (Cattell, 1978), followed by oblique simple structure rotation (Child, 1990). Five factors were extracted, relating to 'positive schizotypy', 'extraverted personality', 
‘neurotic personality’, ‘negative schizotypy’, and ‘psychopathic personality’. Positive schizotypal traits related to symptoms such as magical ideation, perceptual aberration, hallucinations, and delusions. Negative schizotypal traits related to symptoms such as lack of logical thought, lack of appropriate affect, as well as physical and social anhedonia. The factor loadings obtained for each of the five CSTQ factors are shown in Table $1^{2}$.

\section{[Table 1 about here]}

The \pm .10 hyperplane count obtained for the five factor solution was $48.9 \%$, suggesting a better approximation to simple structure criteria than that obtained in the Claridge et al. (1996) study (i.e., a 13.2\% improvement in the hyperplane count). In addition, a LISREL confirmatory factor analysis (cf. Cuttance \& Ecob, 1987) revealed that the five-factor solution provided a better fit to the empirical data than did the corresponding four-factor solution. These findings extended those of Claridge et al. and highlighted the distinction between positive and negative schizotypal traits, which were shown to be distinct from general (Eysenckian) personality dimensions. Furthermore, the positive schizotypal factor also loaded strongly on measures of delusions (especially on Delusions of Disintegration), suggesting that delusional cognition does play an important role in schizotypal personality. Another psychometric instrument (the Schizotypal Personality Questionnaire or SPQ) was designed by Raine (1991) specifically to measure all nine schizotypal personality traits as listed in the DSM-III-R diagnostic criteria for schizotypal personality disorder (also see DSM-IV, Section 301.22). Thus, as compared with the CSTQ (Claridge et al., 1996), which resulted from an attempt to comprehensively measure all major aspects of schizotypy and related constructs (including the Eysenckian personality dimensions), use of the SPQ with

\footnotetext{
${ }^{2}$ Table 1 is adapted from a more comprehensive report of these findings (Boyle, 1998b, p. 116).
} 
its focus on specific diagnostic criteria, provides a very different approach to the measurement of schizotypal traits. In order to further elucidate the factor structure of schizotypal traits, Boyle and Baxter (2004a,b; 2006) performed a series of maximumlikelihood factor analyses with oblique simple-structure rotation of the SPQ subscale intercorrelations. A two-factor solution (presented in Table 2) clearly emerged which separated positive from negative schizotypal traits.

\section{[Table 2 about here]}

A three-factor solution (presented in Table 3) demonstrated that the positive schizotypy factor split into two additional factors.

\section{[Table 3 about here]}

A four-factor solution (presented in Table 4) demonstrated further that the second schizotypy factor now split into two additional factors.

\section{[Table 4 about here]}

These factor analytic findings confirmed that there are both positive and negative schizotypy factors, and that positive schizotypy can be further subdivided into (1) Perceptual Aberration/Magical Thinking, (2) Ideas of Reference/Paranoia, and (3) Odd/Eccentric Behaviour/Speech. 


\section{Schizotypy measures: Implications for disorder}

If schizotypy reflects the phenotypic expression of a genetic predisposition to schizophrenia, a significant proportion of individuals exhibiting schizotypal personality traits would be expected to develop schizophrenia. Schizotypal characteristics in clinical samples have been associated with breakdown rates of $40 \%$ over a 15 -year follow-up (Fenton \& McGlashan, 1989) and 25\% over 2 years (Schultz \& Soloff, 1987). Additionally, $7.6 \%$ of children with schizotypal-like diagnoses at age 10 years received a diagnosis of schizophrenia by age 27 years (Wolff et al., 1991). Studies of individuals in the prodromal phase of schizophrenia with schizotypal features have documented relatively high rates of breakdown for psychosis, for example, 40.8\% over one year (Yung et al., 2003). Others have estimated the breakdown from adolescent schizotypy to schizophrenia to be in the order of 20-40\% (Walker et al., 2004).

Reported rates of breakdown for psychotic disorders in undergraduates showing extreme scores on schizotypal personality are generally much lower. There is mixed evidence as to whether cognitive-perceptual or interpersonal factors of schizotypy are better at predicting later psychosis: one study suggests that physical anhedonia is not predictive (Chapman et al., 1994), while another (Gooding et al., 2005) reports a significantly higher rate of schizophrenia-spectrum disorders in those with high social anhedonia scores (15.6\%), but failed to observe any breakdown in a high-scoring perceptual aberration - magical ideation group (3.4\%). This suggests that interpersonal but not cognitive features may be more predictive of later schizophrenia-related disorders. 


\section{Relationship of schizotypy with the putative 'Big Five' factors of personality}

Studies of the static five-factor model of personality (the so-called 'Big Five': Neuroticism, Extraversion, Openness to Experience, Agreeableness, and Conscientiousness) in relation to schizotypy, SPD, and schizophrenia have produced inconsistent results, potentially because the Big Five does not specifically include a dimension related to abnormal cognition (Costa \& McCrae, 1992). Perhaps the most controversial factor is the status of Openness to Experience in relation to schizotypal personality traits. In SPD patients, one study has found that Openness was elevated (Morey et al., 2002), while other studies report no such relationship (Blais, 1997; Trull, 1992). In studies of psychometrically defined schizotypy, high scores have most commonly been positively associated with Neuroticism and Openness to Experience in undergraduate students (Coolidge et al., 1994; Wiggins \& Pincus, 1989), and negatively associated with Extraversion and Agreeableness (Dyce \& O'Connor, 1998); however, Tien et al. (1992) reported that Openness to Experience was negatively correlated with schizotypy in a community sample, and others have reported no association with Openness to Experience depending upon the type of measure used to define schizotypy (Costa \& McCrae, 1990). Finally, lower levels of Openness to Experience have been reported in studies of schizophrenic patients (Camisa et al., 2005; Gurrera et al., 2005) and their first-degree relatives (Yeung et al., 1993).

Generally, those studies reporting a positive association between schizotypy and Openness to Experience have sampled university undergraduates, while those suggesting a negative association between these constructs have utilised clinical populations (Ross et al., 2002). In clinical populations, elevated schizotypy is most commonly associated with elevated Neuroticism and lower levels of Extraversion, Agreeableness and Conscientiousness, with the exception of Yeung et al. (1993) who found no relationship with Extraversion; Tien 
(1992) who found no association with Agreeableness or Conscientiousness, and Trull (1992), Blais (1997) and Dyce and O’Connor (1998) who found no relationship with Conscientiousness. Evidently, the Big Five personality dimensions (Five Factor Model) fail to provide adequate coverage of the abnormal trait domain (including schizotypal traits). Indeed, Boyle et al. (1995) demonstrated empirically that the Big Five dimensions account for less than $60 \%$ of the known trait variance within the normal personality sphere alone. Part of the difficulty may also reside in the fact that the Big Five dimensions are premised on a relatively outmoded and unduly restrictive static conceptualization of personality structure. Recent empirical studies (e.g., Cattell et al., 2002; Roberts et al., 2006b) suggest that personality structure is subject to learning and substantial developmental change across the entire lifespan (Fraley \& Roberts, 2005; Roberts et al., 2006a), such that personality traits may not represent stable, enduring dispositions as historically thought.

\section{Neurocognition and Psychophysiology}

Studies of cognitive and psychophysiological impairments in schizotypy provide overwhelming evidence for replicable neuro-cognitive impairments that are common to both individuals with clinical psychotic disorder, and ostensibly healthy individuals exhibiting schizotypal personality traits. A relatively wide range of neurocognitive abilities and psychophysiological processes are impacted, with the strongest evidence for impairment in the areas of executive functions, sustained attention, working memory, verbal and spatial learning and memory, latent inhibition, negative priming, hemisphere asymmetry, and motor ability. In general, performance in schizotypy tends to be intermediate between those reporting few or no schizotypal personality traits, and schizophrenia patients (see Raine, 2006). 
Specifically, heightened levels of psychometrically defined schizotypy have been associated with perceptual aberrations (Lenzenweger, 1994) and mild cognitive deficits in sustained (Gooding et al., 2006; Obiols et al., 1999) and selective attention (Moritz \& Mass, 1997; Williams, 1995), disrupted latent inhibition (Tsakanikos et al., 2003), poor executive functioning (Lyons et al., 1991; Moritz et al., 1999; Wilkins \& Venables, 1992), working memory deficits (Tallent \& Gooding, 1999), impaired visual context processing (Uhlhaas et al., 2004), semantic activation deficits (Evans, 1997), as well as aberrant cerebral asymmetry (Goodarzi et al., 2000; Gruzelier et al., 1995; Jutai, 1989; Luh \& Gooding, 1999; Mason \& Claridge, 1999).

The alternative 'high risk' strategy of studying correlates of schizotypy within biological relatives of schizophrenia patients has also shown that family members demonstrate a greater frequency of perceptual aberration (Clementz et al., 1991), attentional disturbance (Balogh \& Merritt, 1985; Laurent et al., 1999; Steinhauer et al., 1991), eye tracking impairments (Blackwood et al., 1991; Waldo \& Freedman, 1999), and electrodermal responding (Claridge et al., 1983), with biologically high-risk children showing a similar psychophysiological profile to their schizophrenic parent (Gruzelier, 1999; Mednick \& Schulsinger, 1968).

Additional psychophysiological similarities between schizophrenia and schizotypy include reduced attentional modulation (Abel et al., 2004; Cadenhead et al., 1993; Cadenhead et al., 2000; Evans et al., 2005; Hazlett et al., 1997; Schell et al., 1995), abnromal electrodermal correlates of the human orienting response (Dawson \& Nuechterlein, 1984), dysfunctions in smooth-pursuit eye-movements (Gooding, 1999; Holahan \& O'Driscoll, 2005; Larrison et 
al., 2000; Lee \& Williams, 2000; Smyrnis et al., 2003), slowed habituation of gamma and beta neural oscillations (Vernon et al., 2005). Behavioural studies within interpersonal domains have also revealed impaired communication (Martin \& Chapman, 1982) and reduced social competence (Haberman et al., 1979; Numbers \& Chapman, 1982) in relation to high levels of schizotypy in the general population.

There has been relatively little study of social-emotional information processing in schizotypy, despite considerable evidence for impaired facial emotion perception in schizophrenia (Edwards et al., 2002; Green et al., 2005) alongside initial findings of poor facial emotion processing in SPD (Mikhailova et al., 1996; Waldeck \& Miller, 2000). Those studies that have examined social information processing in schizotypy, report evidence of poor facial emotion processing (Poreh et al., 1994; van Wout et al., 2004) and increased sensitivity to threat-related stimuli, evident in psychophysiological responses of psychometrically defined schizotypal individuals (Green et al., 2001, 2003; Raine et al., 2002). Initial reports on mentalising also indicate that those high on schizotypy show impaired processing of information related to self (Platek et al., 2005), others (i.e., 'theory of mind'; Langdon \& Coltheart, 1999), and perspective taking skills (Langdon \& Coltheart, 2001).

Finally, despite these impairments, some neuro-cognitive functions appear to be spared or even enhanced in schizotypy. For example, there are no reported IQ deficits in schizotypy. More specifically, several studies suggest enhanced creativity in schizotypy in association with superior verbal fluency (Duchene et al., 1998; Green \& Williams, 1999), and increased right hemisphere functioning (Fisher et al., 2004; Weinstein \& Graves, 2002). Indeed, it has been argued that cognitive inhibitory impairments in schizotypy may paradoxically 
enhance ability to form broad, unusual associations that favour cognitive flexibility and creativity (e.g., Green et al., 1999).

\section{Psychosocial Risk Factors}

Prevailing evidence does not support Meehl’s (1989) hypothesis that schizotypal personality (as opposed to schizophrenia) is not influenced by environmental stressors (such as negative childrearing practices and maternal rejection), and instead gives rise to the counter-hypothesis that negative psychosocial influences are significant risk factors for the development of schizotypal personality, and in particular, the cognitive-perceptual features. For example, initial studies suggest increased child abuse and early trauma in schizotypal individuals compared with controls. Multiple forms of abuse (physical, sexual, emotional, neglect) and post-traumatic stress symptomatology are associated with both higher self-report schizotypy and clinician-assessed symptoms of SPD (Berenbaum et al., 2003). Similar findings have been observed for child abuse and dissociative experiences in high schizotypy scorers (Irwin, 2001; Irwin et al., 1999) and those with high cognitive disorganization scores (Startup, 1999). Furthermore, individuals with SPD (in addition to borderline patients) suffer more types of trauma exposure compared to other personality disordered groups and depressed patients (Yen et al., 2002). Child maltreatment (physical, sexual, emotional) has been associated with increased perceptual aberration and magical ideation scores (Berenbaum, 1999). Similarly, a large-scale community study of 4,045 adults reported a 3.6-fold increase in sub-clinical positive symptoms in those reporting broad-based child abuse (Janssen et al., 2004).

Disturbances in early parental bonding are also associated with schizotypal personality. Anxious attachment has been found to be associated with higher positive schizotypy, while 
avoidant attachment has been associated with both positive and negative symptom schizotypy (Wilson \& Costanzo, 1996). Berenbaum (2003) found neglect to be a particularly salient form of maltreatment in those with schizotypal symptoms, but another study found neglect only non-significantly raised in patients with SPD (85\%) compared to a depressed control group (68\%) (Battle et al., 2004).

Limitations of the above studies include reliance on self-report measures of abuse, neglect, and schizotypy, the lack of official records of neglect, co-morbidity of SPD with other disorders, selected populations, and potential demographic confounds. Overcoming all of these limitations, one study of 738 randomly sampled youths from the community demonstrated that both prospectively-collected maternal reports and official state-verified documentation of both emotional and physical forms of neglect were associated with increased diagnostically-assessed schizotypal symptoms during late adolescence / early adulthood, even after controlling for other personality disorder symptoms, past physical and sexual abuse, and demographic factors (Johnson et al., 2000). Particularly striking was a 4.9-fold increase in SPD in those with physical neglect.

Broader measures of psychosocial adversity and stress in relation to occupational, recreational, and social spheres have also been linked to schizotypy. Two studies controlling for multiple confounds (e.g., IQ) have found increased cognitive-perceptual features of schizotypy to be associated with urban-living (Stefanis et al., 2004). One study observed significantly fewer positive life events, and in particular, an increase in negative life events related to criminal or legal activities in association with SPD (Pagano et al., 2004). These findings suggest a pernicious cycle whereby early stress results in schizotypal 
symptoms that increase social and occupational dysfunction, resulting in further sustained life stress and long-term schizotypal symptomatology.

The notion that schizotypy is associated with a benign psychosocial environment (Meehl 1989) thus no longer seems tenable: schizotypal individuals have significantly impaired family environments. This highlights an unusual point for departure from the tendency for schizotypal individuals to share risk factors in common with schizophrenia as there is little evidence favouring abuse and neglect in the development of schizophrenia. Findings raise the possibility of two subgroups of schizotypy with differing aetiologies: one in whom the genetic liability for schizophrenia accounts for schizotypal symptoms, and another in whom psychosocial adversity contributes to symptomatology (Raine, 2006). One implication for future research is that genetic and neurobiological links to schizotypy may be stronger and more consistent in those schizotypal individuals lacking psychosocial risk factors of abuse and neglect.

Future studies need to both further test the hypothesis of psychosocial risk factors for schizotypy, and address the causal question of why psychosocial factors should result in schizotypal features. One working hypothesis is that early abuse, neglect, and stress results in the structural and functional brain impairments that in turn give rise to schizotypal symptoms. Significant stress during a critical period is thought to result in neurodevelopmental reorganization of the brain (Teicher et al., 2004) and could in part account for structural and functional brain abnormalities associated with schizotypal personality features (see below). Early trauma and stress has also been associated with alterations in glucocorticoid release and increased dopamine levels (Glaser, 2000). Since abuse appears to be somewhat more associated with cognitive-perceptual schizotypy 
features, abuse could partly account for the hypothesized link between these schizotypal features and increased dopamine (Siever, 1995).

Finally, social ramifications of early trauma or neglect should be considered alongside neurobiological explanations. For example, lack of social trust and security resulting from experiencing child abuse could directly predispose to paranoid attributional style, social anxiety, lack of close friends, and more hyper-sensitive, self-referential thinking (Raine, 2006). That this is a feasible causal hypothesis is suggested by the fact that individuals at baseline who lack any lifetime psychotic-like experience but who go on to experience discrimination show an increased rate of clinically-assessed delusional ideation three years later (Janssen et al., 2004). Similarly, disrupted attachment and bonding early in life could result in social-emotional impairments that disrupt normal interpersonal behaviour and predispose to the schizotypal features of lack of close friends, constricted affect, and odd social behaviour.

\section{A Biosocial Neurodevelopmental Model of Schizotypal Personality}

Raine’s (2006) recent model of schizotypy incorporates a neurodevelopmental framework, the operation of psychosocial risk factors, a three-factor conceptualization of schizotypy, and two forms of schizotypy with different etiological paths. In this model, one form of schizotypal personality is termed 'neuro-schizotypy', and is proposed to have origins predominantly (though not exclusively) in the genetic, neurodevelopmental, and neurobiological processes that are shared with schizophrenia, and which predominantly give rise to interpersonal and disorganized features. In contrast, environmental influences largely give rise to 'pseudoschizotypy', a phenocopy of neuroschizotypy, in which cognitive-perceptual features predominate. The differential etiological pathways to the two 
forms of schizotypy are relative rather than absolute; both forms present with clinical features from all three domains, and both likely have contributions from both genes and the environment. Nevertheless, schizophrenia or SPD will only be an outcome for neuroschizotypy, and only when critical protective factors are lacking. These conjectures may be seen to clarify and extend the model of schizotypy originally proposed by Meehl (1989), yet differ in the extent that early environmental factors are not excluded from contributing to either form of schizotypy.

According to Raine (2006), “neuro-schizotypy” is viewed fundamentally as a brain disorder (evident as SPD) with its origins in genetics, early prenatal environmental processes, and early postnatal influences. Genetic factors and prenatal environmental insults are proposed to precipitate structural and functional brain changes that unfold throughout development in frontal, temporal, and limbic regions, and which in turn give rise to psychological abnormalities in cognition and affect. At the same time, postnatal environmental influences (e.g., physical abuse, neglect, poor bonding, discrimination) both contribute to further brain impairment, and also directly result in cognitive and affective disturbances. At the level of personality, while cognitive disturbances primarily shape cognitive-perceptual (e.g., unusual perceptual experiences) and disorganized features (e.g., odd speech), affective disturbances (both CNS and ANS) give rise predominantly to interpersonal deficits (e.g., blunted affect). In addition, both cognitive and affective processes contribute in more limited ways to all three domains of schizotypal symptomatology.

While the basic elements of this model are empirically sound in terms of incorporating current evidence for genetic and environmental processes, cognitive impairments, three factors of schizotypy, and linkage to schizophrenia, other elements (e.g., prenatal and 
postnatal environment, psychosocial risk factors, neurodevelopmental processes) require further empirical scrutiny. For example, empirical support is required for the proposals that: 1. neuro-schizotypy has a relatively stronger genetic and neurobiological basis; an early onset; presents with predominantly interpersonal - disorganized features; is influenced by affective as well as cognitive basic processes; is not associated with significant psychosocial adversity; demonstrates greater symptom stability; is more responsive to psychopharmacological treatments; and presents higher risk for schizophrenia.

2. pseudoschizotypy has a relatively weaker genetic and neurobiological basis; is an outcome of predominantly postnatal environmental and psychosocial influences; presents predominantly with cognitive-perceptual features; may have either an early or late onset; does not progress to schizophrenia; shows symptom fluctuation over time; is less responsive to neurobiological treatment programs; and is more responsive to psychological interventions.

Although the two hypothesized forms of schizotypy cannot be definitively assessed at initial assessment, approximations and alternative strategies to test this model are feasible. Subjects presenting with predominantly interpersonal and disorganized features (though not meeting full DSM-IV criteria for SPD or schizophrenia) may be delineated as putative neuro-schizotypes, while those presenting with predominantly (or even solely) cognitive features may be delineated as putative pseudo-schizotypes. A similar delineation can be taken with questionnaire assessments of schizotypy. Alternatively, schizotypal patients or psychometrically-defined schizotypal individuals could be provisionally delineated as pseudo-schizotypals on the basis of a history of significant psychosocial adversity, while neurodevelopmental schizotypy assignment could be based on a family history of schizophrenia or presence of neurodevelopmental markers. Group differences on symptom 
stability, estimated age of onset, neuro-cognitive markers, candidate gene linkage, treatment efficacy, antisocial behaviour, and symptom presentation could then be tested.

While pseudoschizotypy is postulated to "mimic" the clinical features of neurodevelopmental schizotypy, its status as a true disorder is not questioned, such that it may be no less debilitating. The key difference is that pseudoschizotypy has a somewhat different aetiology, involving more psychosocial influences (cf. Jackson, Vol. 2) and possibly accounting for higher schizotypy in minority groups and co-morbidity for antisocial behaviour. Nevertheless, neurobiological processes likely play some supporting aetiological role in pseudoschizotypy as most of those who experience early bonding, abuse, discrimination, and other psychosocial adversity do not succumb to decompensation into SPD or schizophrenia. 


\section{References}

Abel, K., Jolley, S., Hemsley, D., \& Geyer, M. (2004). The influence of schizotypy traits on prepulse inhibition in young healthy controls. Journal of Psychopharmacology, 18(2), 181-188.

American Psychiatric Association. (1994). Diagnostic and statistical manual of mental disorders ( $4^{\text {th }}$ ed.). Washington, DC: Author.

Andreasen, N. C., Paradiso, S., \& O'Leary, D. S. (1998). "Cognitive dysmetria" as an integrative theory of schizophrenia: A dysfunction in cortical-subcortical-cerebellar circuitry? Schizophrenia Bulletin, 24(2), 203-218.

Arndt, S., Alliger, R. J., \& Andreasen, N. C. (1991). The distinction of positive and negative symptoms: The failure of a two-dimensional model. British Journal of Psychiatry, 158, 317-322.

Axelrod, S. R., Grilo, C. M., Sanislow, C., \& McGlashan, T. H. (2001). Schizotypal personality questionnaire-brief: Factor structure and convergent validity in inpatient adolescents. Journal of Personality Disorders, 15(2), 168-179.

Balogh, D. W., \& Merritt, R. D. (1985). Susceptibility to type a backward pattern masking among hypothetically psychosis-prone college students. Journal of Abnormal Psychology, 94(3), 377-383.

Battle, C. L., Shea, M., Johnson, D. M., Yen, S., Zlotnick, C., Zanarini, M. C., et al. (2004). Childhood maltreatment associated with adult personality disorders: Findings from the collaborative longitudinal personality disorders study. Journal of Personality Disorders Vol 18(2) Apr 2004, 193-211.

Battaglia, M., Cavallini, M. C., Macciardi, F., \& Bellodi, L. (1997). The structure of dsmiii-r schizotypal personality disorder diagnosed by direct interviews. $\underline{\text { Schizophrenia }}$ Bulletin, 23(1), 83-92.

Bentall, R. P., Claridge, G. S., \& Slade, P. D. (1989). The multidimensional nature of schizotypal traits: A factor analytic study with normal subjects. British Journal of Clinical Psychology, 28(4), 363-375.

Berenbaum, H. (1999). Peculiarity and reported childhood maltreatment. Psychiatry: Interpersonal and Biological Processes Vol 62(1) Spr 1999, 21-35.

Berenbaum, H., Valera, E. M., \& Kerns, J. G. (2003). Psychological trauma and schizotypal symptoms. Schizophrenia Bulletin Vol 29(1) 2003, 143-152.

Bergman, A. J., Silverman, J. M., Harvey, P. D., Smith, C. J., \& Siever, L. J. (2000). Schizotypal symptoms in the relatives of schizophrenia patients: An empirical analysis of the factor structure. Schizophrenia Bulletin, 26(3), 577-586. 
Blackwood, D. H., St. Clair, D. M., Muir, W. J., \& Duffy, J. C. (1991). Auditory p300 and eye tracking dysfunction in schizophrenic pedigrees. Archives of General Psychiatry, 48(10), 899-909.

Blais, M. A. (1997). Clinician ratings of the five-factor model of personality and the dsm-iv personality disorders. Journal of Nervous and Mental Disease Vol 185(6) Jun 1997, 388-393.

Boyle, G. J. (1992). Pavlovian Temperament Survey (PTS): Australian normative data. In J. Strelau, A. Angleitner, \& B. H. Newberry (1999). The Pavlovian Temperament Survey (PTS): An international handbook (pp. 78-84). Seattle, WA: Hogrefe \& Huber.

Boyle, G. J. (1998a). [Review of the Rust Inventory of Schizotypal Cognitions.] In J. Impara \& B. Plake (Eds.), The thirteenth mental measurements yearbook (pp. 860861). Lincoln, NE: Buros Institute of Mental Measurements.

Boyle, G. J. (1998b). Schizotypal personality traits: An extension of previous psychometric investigations. Australian Journal of Psychology, 50(2), 114-118.

Boyle, G. J. (2003). Schizotypal personality traits: Factor structure. Paper presented at the $17^{\text {th }}$ World Congress on Psychosomatic Medicine, Waikoloa, Hawaii, USA, August 23-28.

Boyle, G. J., \& Baxter, T. C. (2004a). Redefining the factor structure of schizotypal personality traits. Paper presented at the $16^{\text {th }}$ Annual Convention, American Psychological Society, Chicago, May 27-30.

Boyle, G. J., \& Baxter, T. C. (2004b). Factor structure of the Schizotypal Personality Questionnaire (SPQ). Paper presented at the $28^{\text {th }}$ International Congress of Psychology, Beijing, August 8-14.

Boyle, G. J., \& Baxter, T. C. (2006). Factor structure of schizotypal personality traits. Paper presented at the $9^{\text {th }}$ International Congress of Behavioral Medicine, Bangkok, November 29 - December 2.

Boyle, G. J., Stankov, L., \& Cattell, R. B. (1995). Measurement and statistical models in the study of personality and intelligence. In D. H. Saklofske \& M. Zeidner (Eds.), International handbook of personality and intelligence (pp. 281-329). New York: Plenum.

Boyle, M. (1990). Schizophrenia: A scientific delusion? London, UK: Routledge.

Cadenhead, K. S., Geyer, M. A., \& Braff, D. L. (1993). Impaired startle prepulse inhibition and habituation in patients with schizotypal personality disorder. American Journal of Psychiatry, 150(12), 1862-1867. 
Cadenhead, K. S., Light, G. A., Geyer, M. A., \& Braff, D. L. (2000). Sensory gating deficits assessed by the p50 event-related potential in subjects with schizotypal personality disorder. American Journal of Psychiatry, 157(1), 55-59.

Calkins, M. E., Curtis, C. E., Grove, W. M., \& lacono, W. G. (2004). Multiple dimensions of schizotypy in first degree biological relatives of schizophrenia patients. Schizophrenia Bulletin, 30(2), 317-325.

Camisa, K. M., Bockbrader, M. A., Lysaker, P., Rae, L. L., Brenner, C. A., \& O'Donnell, B. F. (2005). Personality traits in schizophrenia and related personality disorders. Psychiatry Research, 133(1), 23-33.

Cattell, R. B. (1978). The scientific use of factor analysis in behavioral and life sciences. New York: Plenum.

Cattell, R. B., Boyle, G. J., \& Chant, D. (2002). Enriched behavioral prediction equation and its impact on structured learning and the dynamic calculus. Psychological Review, 109, 202-205.

Chapman, L. J., Chapman, J. P., Kwapil, T. R., \& Eckblad, M. (1994). Putatively psychosis-prone subjects 10 years later. J Abnormal Psychology, 103(2), 171-183.

Chapman, L. J., Chapman, J. P., \& Raulin, M. L. (1976). Scales for physical and social anhedonia. Journal of Abnormal Psychology, 85(4), 374-382.

Chapman, L. J., Chapman, J. P., \& Raulin, M. L. (1978). Body-image aberration in schizophrenia. Journal of Abnormal Psychology, 87(4), 399-407.

Chapman, L. J., Edell, W. S., \& Chapman, J. P. (1980). Physical anhedonia, perceptual aberration, and psychosis proneness. Schizophrenia Bulletin, 6(4), 639-653.

Chen, W. J., Hsiao, C. K., \& Lin, C. C. H. (1997). Schizotypy in community samples: The three-factor structure and correlation with sustained attention. Journal of Abnormal Psychology, 106(4), 649-654.

Child, D. (1990). The essentials of factor analysis (rev. $2^{\text {nd }}$ ed.), London: Cassell.

Claridge, G. S. (1994). Single indicator of risk for schizophrenia: Probable fact or likely myth? Schizophrenia Bulletin, 20(1), 151-168.

Claridge, G. S. (1997). Schizotypy: Implications for illness and health. Oxford, UK: Oxford University Press.

Claridge, G., S. \& Beech, A. (1995). Fully and quasi-dimensional constructions of schizotypy. In A. Raine \& T. Lencz (Eds.), Schizotypal personality (pp. 192-216). New York: Cambridge. 
Claridge, G. S., \& Beech, A. (1996). Schizotypy and lateralised negative priming in schizophrenics' and neurotics' relatives. Personality and Individual Differences, 20(2), 193-199.

Claridge, G. S., \& Broks, P. (1984). Schizotypy and hemisphere function: I. Theoretical considerations and the measurement of schizotypy. Personality \& Individual Differences, 5(6), 633-648.

Claridge, G. S., McCreery, C., Mason, O., Bentall, R., Boyle, G. J., Slade, P., \& Popplewell, D. (1996). The factor structure of "schizotypal" traits: A large replication study. British Journal of Clinical Psychology, 35(1), 103-115.

Claridge, G. S., Robinson, D. L., \& Birchall, P. (1983). Characteristics of schizophrenics' and neurotics' relatives. Personality and Individual Differences, 4(6), 651-664.

Claridge, G. S. (1985). Origins of mental illness. Oxford, UK: Blackwell.

Clementz, B. A., Grove, W. M., Katsanis, J., \& Iacono, W. G. (1991). Psychometric detection of schizotypy: Perceptual aberration and physical anhedonia in relatives of schizophrenics. Journal of Abnormal Psychology, 100(4), 607-612.

Coolidge, F. L., Becker, L. A., DiRito, D. C., Durham, R. L., \& et al. (1994). On the relationship of the five-factor personality model to personality disorders: Four reservations. Psychological Reports, 75(1), 11-21.

Costa, P. T., \& McCrae, R. R. (1990). Personality disorders and the five-factor model of personality. Journal of Personality Disorders, 4(4), 362-371.

Costa, P. T., \& McCrae, R. R. (1992). The five-factor model of personality and its relevance to personality disorders. Journal of Personality Disorders, 6(4), 343-359.

Cuttance, P., \& Ecob, R. (Eds.). (1987). Structural modeling by example: Applications in educational, sociological, and behavioral research. New York: Cambridge.

Dawson, M. E., \& Nuechterlein, K. H. (1984). Psychophysiological dysfunctions in the developmental course of schizophrenic disorders. Schizophrenia Bulletin, 10(2), 204-232.

Dolan, R.J., Fletcher, P.C., McKenna, P., Friston, K. J., Frith, C.D. (1999). Abnormal neural integration related to cognition in schizophrenia. Acta Psychiatrica Scandinavica, 99(Suppl 395), 58-67.

Duchene, A., Graves, R. E., \& Brugger, P. (1998). Schizotypal thinking and associative processing: A response commonality analysis of verbal fluency. Journal of Psychiatry and Neuroscience, 23(1), 56-60.

Dyce, J. A., \& O'Connor, B. P. (1998). Personality disorders and the five-factor model: A test of facet-level predictions. Journal of Personality Disorders, 12(1), 31-45. 
Eckblad, M., \& Chapman, L. J. (1983). Magical ideation as an indicator of schizotypy. Journal of Consulting and Clinical Psychology, 51(2), 215-225.

Eckblad, M., \& Chapman, L. J. (1986). Development and validation of a scale for hypomanic personality. Journal of Abnormal Psychology, 95(3), 214-222.

Edwards, J., Jackson, H. J., \& Pattison, P. E. (2002). Emotion recognition via facial expression and affective prosody in schizophrenia: A methodological review. Clinical Psychology Review, 22(6), 789-832.

Evans, J. L. (1997). Semantic activation and preconscious processing in schizophrenia and schizotypy. In G. S. Claridge (Ed.), Schizotypy: Implications for illness and health. (pp. 80-97). Oxford, UK: Oxford University Press.

Evans, L. H., Gray, N. S., \& Snowden, R. J. (2005). Prepulse inhibition of startle and its moderation by schizotypy and smoking. Psychophysiology, 42(2), 223-231.

Eysenck, H. J. (1947). Dimensions of personality. London: Kegan Paul.

Eysenck, H. J. (1960). Classification and the problem of diagnosis. In H. J. Eysenck (Ed.), Handbook of abnormal psychology. London: Pitman.

Eysenck, H. J., \& Eysenck, S. B. G. (1975). Manual of the Eysenck Personality Questionnaire. London: Hodder \& Stoughton.

Eysenck, H. J., \& Eysenck, S. B. G. (1977). Psychoticism as a dimension of personality. New York: Carne \& Russak.

Fenton, W. S., \& McGlashan, T. H. (1989). Risk of schizophrenia in character disordered patients. American Journal of Psychiatry, 146(10), 1280-1284.

Fisher, J. E., Mohanty, A., Herrington, J. D., Koven, N. S., Miller, G. A., \& Heller, W. (2004). Neuropsychological evidence for dimensional schizotypy: Implications for creativity and psychopathology. Journal of Research in Personality, 38(1), 24-31.

Fossati, A., Raine, A., Carretta, I., Leonardi, B., \& Maffei, C. (2003). The three-factor model of schizotypal personality: Invariance across age and gender. Personality and Individual Differences, 35(5), 1007-1019.

Foulds, G. A., \& Bedford, A. (1975). Hierarchy of classes of personal illness. Psychological Medicine, 5, 181-192.

Fraley, R. C., \& Roberts, B. W. (2005). Patterns of continuity: A dynamic model for conceptualizing the stability of individual differences on psychological constructs across the life course. Psychological Review, 112, 60-74.

Friston, K. J. (1999a). The disconnection hypothesis. Schizophrenia Research, 30, 115-125. 
Friston, K. J. (1999b). Schizophrenia and the disconnection hypothesis. Acta Psychiatrica Scandinavica, 99(Suppl 395), 68-79.

Glaser, D. (2000). Child abuse and neglect and the brain--a review. Journal of Child Psychology and Psychiatry, 41(1), 97-116.

Gold, S., Arndt, S., Nopoulos, P., O'Leary, D. S., \& Andreasen, N. C. (1999). Longitudinal study of cognitive function in first-episode and recent-onset schizophrenia. American Journal of Psychiatry, 156(9), 1342-1348.

Golden, R. R; \& Meehl, P. E. (1979). Detection of the schizoid taxon with MMPI indicators. Journal of Abnormal Psychology, 88(3), 217-233.

Goodarzi, M. A., Wykes, T., \& Hemsley, D. R. (2000). Cerebral lateralization of globallocal processing in people with schizotypy. Schizophrenia Research, 45(1-2), 115121.

Gooding, D. C. (1999). Antisaccade task performance in questionnaire-identified schizotypes. Schizophrenia Research, 35(2), 157-166.

Gooding, D. C., Matts, C. W., \& Rollmann, E. A. (2006). Sustained attention deficits in relation to psychometrically identified schizotypy: Evaluating a potential endophenotypic marker. Schizophrenia Research, 82(1), 27-37.

Gooding, D. C., Tallent, K. A., \& Matts, C. W. (2005). Clinical status of at-risk individuals 5 years later: Further validation of the psychometric high-risk strategy. Journal of Abnormal Psychology, 114(1), 170-175.

Goulding, A. (2004). Schizotypy models in relation to subjective health and paranormal beliefs and experiences. Personality and Individual Differences, 37(1), 157-167.

Gottesman, I. I., \& Shields, J. (1972). Schizophrenia and genetics: A twin study vantage point. New York: Academic.

Green, M. J., Uhlhaas, P. J., \& Coltheart, M. (2005). Context processing and social cognition in schizophrenia. Curent Psychiatry Reviews, 1(1), 11-21.

Green, M. J., \& Williams, L. M. (1999). Schizotypy and creativity as effects of reduced cognitive inhibition. Personality \& Individual Differences, 27(2), 263-276.

Green, M. J., Williams, L. M., \& Davidson, D. (2003). Visual scanpaths and facial affect recognition in delusion-prone individuals: Increased sensitivity to threat? Cognitive Neuropsychiatry, 8(1), 19-41.

Green, M. J., Williams, L. M., \& Davidson, D. J. (2001). Processing of threat-related affect is delayed in delusion-prone individuals. British Journal of Clinical Psychology, 40(2), 157-165. 
Grossarth-Maticek, R., Eysenck, H. J., \& Boyle, G. J. (1994). An empirical study of the diathesis-stress theory of disease. International Journal of Stress Management, 1, 318.

Grossberg, S. (2000). The imbalanced brain: From normal behavior to schizophrenia. Biological Psychiatry, 48(2), 81-98.

Gruzelier, J. (1999). Implications of early sensory processing and subcortical involvement for cognitive dysfunction in schizophrenia. In C. A. Tamminga (Ed.), Schizophrenia in a molecular age. Review of psychiatry series (pp. 29-75). Washington, DC: American Psychiatric Press.

Gruzelier, J., Burgess, A., Stygall, J., Irving, G., \& Raine, A. (1995). Patterns of cognitive asymmetry and syndromes of schizotypal personality. Psychiatry Research, 56(1), 71-79.

Gurrera, R. J., Dickey, C. C., Niznikiewicz, M. A., Voglmaier, M. M., Shenton, M. E., \& McCarley, R. W. (2005). The five-factor model in schizotypal personality disorder. Schizophrenia Research, 80(2-3), 243-251.

Haberman, M. C., Chapman, L. J., Numbers, J. S., \& McFall, R. M. (1979). Relation of social competence to scores on two scales of psychosis proneness. Journal of Abnormal Psychology, 88(6), 675-677.

Hanssen, M., Bak, M., Bijl, R., Vollebergh, W., \& van Os, J. (2005). The incidence and outcome of subclinical psychotic experiences in the general population. British Journal of Clinical Psychology, 44(2), 181-191.

Hazlett, E. A., Dawson, M. E., Filion, D. L., Schell, A. M., \& Nuechterlein, K. H. (1997). Autonomic orienting and the allocation of processing resources in schizophrenia patients and putatively at-risk individuals. Journal of Abnormal Psychology, 106(2), 171-181.

Hewitt, J. K., \& Claridge, G. (1989). The factor structure of schizotypy in a normal population. Personality \& Individual Differences, 10(3), 323-329.

Holahan, A.-L. V., \& O'Driscoll, G. A. (2005). Antisaccade and smooth pursuit performance in positive- and negative-symptom schizotypy. Schizophrenia Research, 76(1), 43-54.

Irwin, H. J. (2001). The relationship between dissociative tendencies and schizotypy: An artifact of childhood trauma? Journal of Clinical Psychology, 57(3), 331-342.

Irwin, H. J., Green, M. J., \& Marsh, P. J. (1999). Dysfunction in smooth pursuit eye movements and history of childhood trauma. Perceptual \& Motor Skills, 89(3), Pt 2), 1230-1236. 
Janssen, I., Krabbendam, L., Bak, M., Hanssen, M., Vollebergh, W., de Graaf, R., et al. (2004). Childhood abuse as a risk factor for psychotic experiences. Acta Psychiatrica Scandinavica, 109(1), 38-45.

Johns, L. C., \& van Os, J. (2001). The continuity of psychotic experiences in the general population. Clinical Psychology Review, 21(8), 1125-1141.

Johnson, J. J., Smailes, E. M., Cohen, P., Brown, J., \& Bernstein, D. P. (2000). Associations between four types of childhood neglect and personality disorder symptoms during adolescence and early adulthood: Findings of a community-based longitudinal study. Journal of Personality Disorders, 14(2), 171-187.

Jutai, J. W. (1989). Spatial attention in hypothetically psychosis-prone college students. Psychiatry Research, 27(2), 207-215.

Kelley, M. P., \& Coursey, R. D. (1992). Factor structure of schizotypy scales. Personality and Individual Differences, 13(6), 723-731.

Kender, K. S., \& Diehl, S. R. (1993). The genetics of schizophrenia: A current geneticepidemiologic perspective. Schizophrenia Bulletin, 19(2), 261-285.

Kendler, K. S., \& Hewitt, J. (1992). The structure of self-report schizotypy in twins. Journal of Personality Disorders, 6(1), 1-17.

Kraepelin, E. (1913). Dementia praecox and paraphrenia (trans. 1919 by R.M. Barclay). Edinburgh, UK: Livingstone.

Langdon, R., \& Coltheart, M. (1999). Mentalising, schizotypy, and schizophrenia. Cognition, 71(1), 43-71.

Langdon, R., \& Coltheart, M. (2001). Visual perspective-taking and schizotypy: Evidence for a simulation-based account of mentalising in normal adults. Cognition, 82, 1-26.

Larrison, A. L., Ferrante, C. F., Briand, K. A., \& Sereno, A. B. (2000). Schizotypal traits, attention and eye movements. Progress in Neuro-Psychopharmacology and Biological Psychiatry, 24(3), 357-372.

Launay, G., \& Slade, P. D. (1981). The measurement of hallucinatory predisposition in male and female prisoners. Personality and Individual Differences, 2(3), 221-234.

Laurent, A., Saoud, M., Bougerol, T., d'Amato, T., Anchisi, A., Biloa-Tang, M., et al. (1999). Attentional deficits in patients with schizophrenia and in their non-psychotic first-degree relatives. Psychiatry Research, 89(3), 147-159.

Lee, K.-H., \& Williams, L. M. (2000). Eye movement dysfunction as a biological marker of risk for schizophrenia. Australian and New Zealand Journal of Psychiatry, 34(Suppl), S91-S100. 
Lenzenweger, M. F. (1994). Psychometric high-risk paradigm, perceptual aberrations, and schizotypy: An update. Schizophrenia Bulletin, 20(1), 121-135.

Lenzenweger, M. F. (2006). Schizotaxia, schizotypy, and schizophrenia: Paul e. Meehl's blueprint for the experimental psychopathology and genetics of schizophrenia. Journal of Abnormal Psychology, 115(2), 195-200.

Liddle, P. F. (1987). The symptoms of chronic schizophrenia: A re-examination of the positive and negative dichotomy. British Journal of Psychiatry, 151, 145-151.

Luh, K. E., \& Gooding, D. C. (1999). Perceptual biases in psychosis-prone individuals. Journal of Abnormal Psychology, 108(2), 283-289.

Lyons, M. J., Merla, M. E., Young, L., \& Kremen, W. S. (1991). Impaired neuropsychological functioning in symptomatic volunteers with schizotypy: Preliminary findings. Biological Psychiatry, 30(4), 424-426.

Martin, E. M., \& Chapman, L. J. (1982). Communication effectiveness in psychosis-prone college students. Journal of Abnormal Psychology, 91(6), 420-425.

Mason, O. (1995). A confirmatory factor analysis of the structure of schizotypy. European Journal of Personality, 9(4), 271-281.

Mason, O., \& Claridge, G. (1999). Individual differences in schizotypy and reduced asymmetry using the chimeric faces task. Cognitive Neuropsychiatry, 4(4), 289301.

Mason, O., \& Claridge, G. (2006). The oxford-liverpool inventory of feelings and experiences (o-life): Further description and extended norms. Schizophrenia Research, 82(2-3), 203-211.

Mason, O., Claridge, G., \& Jackson, M. (1995). New scales for the assessment of schizotypy. Personality and Individual Differences, 18(1), 7-13.

Mason, O., Claridge, G., \& Williams, L. (1997). Questionnaire measurement. In G. Claridge (Ed.), Schizotypy: Implications for illness and health (pp. 19-37). Oxford, UK: Oxford University Press.

Mason, O., Linney, Y., \& Claridge, G. (2005). Short scales for measuring schizotypy. Schizophrenia Research, 78(2-3), 293-296.

Mednick, S. A., \& Schulsinger, F. (1968). Some premorbid characteristics related to breakdown in children wirh schizophrenic mothers. In D. Rosenthal \& S. S. Kety (Eds.), The transmission of schizophrenia. Oxford, UK: Pergamon.

Meehl, P. E. (1962). Schizotaxia, schizotypy, schizophrenia. American Psychologist, 17(12), 827-838.

Meehl, P. E. (1989). Schizotaxia revisited. Archives of General Psychiatry, 46, 935-943. 
Meehl, P. E. (1990). Toward an integrated theory of schizotaxia, schizotypy, and schizophrenia. Journal of Personality Disorders, 4(1), 1-99.

Mikhailova, E. S., Vladimirova, T. V., Iznak, A. F., Tsusulkovskaya, E. J., \& et al. (1996). Abnormal recognition of facial expression of emotions in depressed patients with major depression disorder and schizotypal personality disorder. Biological Psychiatry Vol 40(8), 697-705.

Montag, I., \& Levin, J. (1992). Personality correlates of schizotypy factors. Personality and Individual Differences, 13(5), 545-548.

Morey, L. C., Gunderson, J. G., Quigley, B. D., Shea, M., Skodol, A. E., McGlashan, T. H., et al. (2002). The representation of borderline, avoidant, obsessive-compulsive, and schizotypal personality disorders by the five-factor model. Journal of Personality Disorders, 16(3), 215-234.

Moritz, S., Andresen, B., Naber, D., Krausz, M., \& Probsthein, E. (1999). Neuropsychological correlates of schizotypal disorganisation. Cognitive Neuropsychiatry, 4(4), 343-349.

Moritz, S., \& Mass, R. (1997). Reduced cognitive inhibition in schizotypy. British Journal of Clinical Psychology, 36(3), 365-376.

Nielsen, T. C., \& Petersen, K. E. (1976). Electrodermal correlates of extraversion, trait anxiety, and schizophrenism. Scandinavian Journal of Psychology, 17(2), 73-80.

Numbers, J. S., \& Chapman, L. J. (1982). Social deficits in hypothetically psychosis-prone college women. Journal of Abnormal Psychology, 91(4), 255-260.

Obiols, J. E., Serrano, F., Caparros, B., Subira, S., \& Barrantes, N. (1999). Neurological soft signs in adolescents with poor performance on the continuous performance test: Markers of liability for schizophrenia spectrum disorders? Psychiatry Research, 86(3), 217-228.

Ortet, G., Ibanex, M. I., Moro, M., Silva, F., \& Boyle, G. J. (1999). Psychometric appraisal of Eysenck's revised Psychoticism scale: A cross-cultural study. Personality and Individual Differences, 27(6), 1209-1219.

Pagano, M. E., Skodol, A., Stout, R., Shea, M., Yen, S., Grilo, C., et al. (2004). Stressful life events as predictors of functioning: Findings from the collaborative longitudinal personality disorders study. Acta Psychiatrica Scandinavica, 110(6), 421-429.

Pavlov, I. P. (1928). Lectures on conditioned reflexes. New York: Liveright.

Peralta, V., Cuesta, M. J., \& Farre, C. (1997). Factor structure of symptoms in functional psychoses. Biological Psychiatry, 42(9), 806-815. 
Peters, E. R., Joseph, S. A., \& Garety, P. A. (1999). Measurement of delusional ideation in the normal population: Introducing the PDI (Peters et al. Delusions Inventory). Schizophrenia Bulletin, 25(3), 553-576.

Platek, S. M., Fonteyn, L. C., Myers, T. E., Izzetoglu, M., Ayaz, H., Li, C., et al. (2005). Functional near infrared spectroscopy reveals differences in self-other processing as a function of schizotypal personality traits. Schizophrenia Research, 73(1), 125-127.

Poreh, A. M., Whitman, R. D., Weber, M., \& Ross, T. (1994). Facial recognition in hypothetically schizotypic college students: The role of generalized poor performance. Journal of Nervous \& Mental Disease, 182(9), 503-507.

Rado, S. (1953). Dynamics and classification of disordered behavior. American Journal of Psychiatry, 110, 406-426.

Raine, A. (1991). The SPQ: A scale for the assessment of schizotypal personality based on DSM-III-R criteria. Schizophrenia Bulletin, 17(4), 555-564.

Raine, A. (2006). Schizotypal personality: Neurodevelopmental and psychosocial trajectories. Annual Review of Clinical Psychology, 2, 291-326.

Raine, A., \& Allbutt, J. (1989). Factors of schizoid personality. British Journal of Clinical Psychology, 28(1), 31-40.

Raine, A., Lencz, T., Mednick, S. A., \& Sarnoff, A. (Eds.). (1995). Schizotypal personality. New York: Cambridge University Press.

Raine, A., Reynolds, C., Lencz, T., Scerbo, A., Triphon, N., \& Kim, D. (1994). Cognitiveperceptual, interpersonal, and disorganized features of schizotypal personality. Schizophrenia Bulletin, 20(1), 191-201.

Raine, A., Venables, P. H., Mednick, S., \& Mellingen, K. (2002). Increased psychophysiological arousal and orienting at ages 3 and 11 years in persistently schizotypal adults. Schizophrenia Research, 54(1-2), 77-85.

Rawlings, D., \& Freeman, J. L. (1996). A questionnaire for the measurement of paranoia/suspiciousness. British Journal of Clinical Psychology, 35(3), 451-461.

Rawlings, D., \& MacFarlane, C. (1994). A multidimensional schizotypal traits questionnaire for young adolescents. Personality and Individual Differences, 17(4), 489-496.

Reynolds, C. A., Raine, A., Mellingen, K., Venables, P. H., \& Mednick, S. A. (2000). Three-factor model of schizotypal personality: Invariance across culture, gender, religious affiliation, family adversity, and psychopathology. Schizophrenia Bulletin, 26(3), 603-618. 
Roberts, B. W., Walton, K. E., Viechtbauer, W. (2006a). Patterns of mean-level change in personality traits across the life course: A meta-analysis of longitudinal studies. Psychological Bulletin, 132, 1-25.

Roberts, B. W., Walton, K. E., Viechtbauer, W. (2006b). Personality traits change in adulthood: Reply to Costa and McCrae (2006). Psychological Bulletin, 132, 29-32.

Rosa, A., van Os, J., Fananas, L., Barrantes, N., Caparros, B., Gutierrez, B., \& Obiols, J. (2000). Developmental instability and schizotypy. Schizophrenia Research, 43(2-3), 125-134.

Ross, S. R., Lutz, C. J., \& Bailley, S. E. (2002). Positive and negative symptoms of schizotypy and the five-factor model: A domain and facet level analysis. Journal of Personality Assessment, 79(1), 53-72.

Rust, J. (1988). The rust inventory of schizotypal cognitions (RISC). Schizophrenia Bulletin, 14(2), 317-322.

Schell, A. M., Dawson, M. E., Hazlett, E. A., \& Filion, D. L. (1995). Attentional modulation of startle in psychosis-prone college students. Psychophysiology, 32(3), 266-273.

Schultz, S. C., \& Soloff, P. H. (1987). Still borderline after all these years. Paper presented at the 140th Annual Meeting of the American Psychiatric Association, New York.

Siever, L. J. (1995). Brain structure/function and the dopamine system in schizotypal personality disorder: In A. Raine, T. Lencz, \& S. A. Mednick, (Eds.), Schizotypal personality (pp. 272-286). New York, NY: Cambridge.

Siever, L. J., Kalus, O. F., \& Keefe, R. S. (1993). The boundaries of schizophrenia. Psychiatric Clinics of North America, 16(2), 217-244.

Smyrnis, N., Evdokimidis, I., Stefanis, N. C., Avramopoulos, D., Constantinidis, T. S., Stavropoulos, A., \& Stefanis, C. N. (2003). Antisaccade performance of 1,273 men: Effects of schizotypy, anxiety, and depression. Journal of Abnormal Psychology, 112(3) 403-414.

Startup, M. (1999). Schizotypy, dissociative experiences and childhood abuse:

Relationships among self-report measures. British Journal of Clinical Psychology, 38(4), 333-344.

Stefanis, N., Delespaul, P., Lembesi, A., Avramopoulos, D., Evdokimidis, I., Stefanis, C., et al. (2004). Is the excess risk of psychosis-like experiences in urban areas attributable to altered cognitive development? Social Psychiatry and Psychiatric Epidemiology, 39(5), 364-368.

Steinhauer, S. R., Zubin, J., Condray, R., Shaw, D. B., Peters, J. L., \& van Kammen, D. P. (1991). Electrophysiological and behavioral signs of attentional disturbance in 
schizophrenics and their siblings. In C. A. Tamminga, \& C. S. Schulz (Eds.), Schizophrenia research. Advances in neuropsychiatry and psychopharmacology, Vol. 1 (pp. 169-178). New York: Raven.

Tallent, K. A., \& Gooding, D. C. (1999). Working memory and Wisconsin card sorting test performance in schizotypic individuals: A replication and extension. Psychiatry Research, 89(3), 161-170.

Teicher, M. H., Dumont, N. L., Ito, Y., Vaituzis, C., Giedd, J. N., \& Andersen, S. L. (2004). Childhood neglect is associated with reduced corpus callosum area. Biological Psychiatry, 56(2), 80-85.

Thompson, P. A., \& Meltzer, H. Y. (1993). Positive, negative, and disorganisation factors from the schedule for affective disorders and schizophrenia and the present state examination: A three-factor solution. British Journal of Psychiatry, 163, 344-351.

Tien, A. Y., Costa, P. T., \& Eaton, W. W. (1992). Covariance of personality, neurocognition, and schizophrenia spectrum traits in the community. Schizophrenia Research, 7(2), 149-158.

Trull, T. J. (1992). DSM-III-R personality disorders and the five-factor model of personality: An empirical comparison. Journal of Abnormal Psychology, 101(3), 553-560.

Tsakanikos, E., Sverdrup-Thygenson, L., \& Reed, P. (2003). Latent inhibition and psychosis-proneness: Visual search as a function of pre-exposure to the target and schizotypy level. Personality and Individual Differences, 34(4), 575-589.

Tyrka, A. R., Cannon, T. D., Haslam, N., Mednick, S. A., et al. The latent structure of schizotypy: I. Premorbid indicators of a taxon of individuals at risk for schizophrenia-spectrum disorders. Journal of Abnormal Psychology, 104(1), 173183.

Uhlhaas, P. J., Silverstein, S. M., Phillips, W. A., \& Lovell, P. G. (2004). Evidence for impaired visual context processing in schizotypy with thought disorder. Schizophrenia Research, 68(2-3), 249-260.

van Os, J., Hanssen, M., Bijl, R. V., \& Ravelli, A. (2000). Strauss (1969) revisited: A psychosis continuum in the general population? Schizophrenia Research, 45(1-2), $11-20$.

van Os, J., Hanssen, M., Bijl, R. V., \& Vollebergh, W. (2001). Prevalence of psychotic disorder and community level of psychotic symptoms - an urban-rural comparison. Archives of General Psychiatry, 58(7), 663-668.

van Wout, M., Aleman, A., Kessels, R. P., Laroi, F., \& Kahn, R. S. (2004). Emotional processing in a non-clinical psychosis-prone sample. Schizophrenia Research, $\underline{68(2-3)}$, 271-281. 
Venables, P. H., \& Rector, N. A. (2000). The content and structure of schizotypy: A study using confirmatory factor analysis. Schizophrenia Bulletin, 26(3), 587-602.

Vernon, D., Haenschel, C., Dwivedi, P., \& Gruzelier, J. (2005). Slow habituation of induced gamma and beta oscillations in association with unreality experiences in schizotypy. International Journal of Psychophysiology, 56(1), 15-24.

Vollema, M. G., \& van den Bosch, R. J. (1995). The multidimensionality of schizotypy. Schizophrenia Bulletin, 21(1), 19-31.

Waldeck, T. L., \& Miller, L. (2000). Social skills deficits in schizotypal personality disorder. Psychiatry Research, 93(3), 237-246.

Waldo, M. C., \& Freedman, R. (1999). Neurobiological abnormalities in the relatives of schizophrenics. Journal of Psychiatric Research, 33(6), 491-495.

Walker, E., Kestler, L., Bollini, A., \& Hochman, K. M. (2004). Schizophrenia: Etiology and course. Annual Review of Psychology, 55, 401-430.

Weinstein, S., \& Graves, R. E. (2002). Are creativity and schizotypy products of a right hemisphere bias? Brain and Cognition, 49(1), 138-151.

Wiggins, J. S., \& Pincus, A. L. (1989). Conceptions of personality disorders and dimensions of personality. Psychological Assessment, 1(4), 305-316.

Wilkins, S., \& Venables, P. H. (1992). Disorder of attention in individuals with schizotypal personality. Schizophrenia Bulletin, 18(4), 717-723.

Williams, L. M. (1995). Further evidence for a multidimensional personality disposition to schizophrenia in terms of cognitive inhibition. British Journal of Clinical Psychology, 34(2), 193-213.

Williams, L. M., Phillips, M. L., Gordon, E., Lagopolous, J., Rennie, C., Brammer, M. J. et al. (2000). Functional neuroimaging and threat perception in paranoia: Neural responses are differentiated by simultaneously recorded skin conductance responses. Schizophrenia Research, 41, 142-143.

Wilson, J. S., \& Costanzo, P. R. (1996). A preliminary study of attachment, attention, and schizotypy in early adulthood. Journal of Social \& Clinical Psychology, 15(2), 231260.

Wolff, S., Townshend, R., McGuire, R. J., \& Weeks, D. J. (1991). 'Schizoid' personality in childhood and adult life. II: Adult adjustment and the continuity with schizotypal personality disorder. British Journal of Psychiatry, 159, 620-629.

Yen, S., Shea, M., Battle, C. L., Johnson, D. M., Zlotnick, C., Dolan-Sewell, R. et al. (2002). Traumatic exposure and posttraumatic stress disorder in borderline, schizotypal, avoidant and obsessive-compulsive personality disorders: Findings 
from the collaborative longitudinal personality disorders study. Journal of Nervous and Mental Disease, 190(8), 510-518.

Yeung, A. S., Lyons, M. J., Waternaux, C. M., Faraone, S. V. et al. (1993). The relationship between DSMII personality disorders and the five-factor model of personality. Comprehensive Psychiatry, 34(4), 227-234.

Yung, A. R., Phillips, L. J., Yuen, H. P., Francey, S. M., McFarlane, C. A., Hallgren, M., et al. (2003). Psychosis prediction: 12-month follow up of a high-risk ("prodromal") group. Schizophrenia Research, 60(1), 21-32. 
Table 1: Loadings for five CSTQ factors.

\begin{tabular}{|l|c|c|c|c|c|}
\hline \multirow{2}{*}{\multicolumn{1}{c|}{ Psychometric Scales }} & \multicolumn{5}{c|}{ CSTQ Factor loadings } \\
\cline { 2 - 6 } & Factor 1 & Factor 2 & Factor 3 & Factor 4 & Factor 5 \\
\hline Claridge STA & .59 & -- & .48 & -- & -- \\
\hline Claridge STB & -- & -- & .58 & -- & .37 \\
\hline Magical Ideation & .86 & -- & -- & -- & -- \\
\hline Perceptual Aberration & .81 & -- & -- & -- & -- \\
\hline Delusions of Persecution & .38 & -- & -- & -- & -- \\
\hline Delusions of Grandeur & .45 & -- & -- & -- & -- \\
\hline Delusions of Disintegration & .82 & -- & -- & -- & -- \\
\hline Hypomanic Personality & .42 & .47 & -- & -- & -- \\
\hline Social Anhedonia & -- & -.41 & -- & .38 & -- \\
\hline Physical Anhedonia & -- & -- & -- & .59 & -- \\
\hline Schizophrenism Scale & -- & -- & .73 & -- & -- \\
\hline MMPI Schizoidia Scale & -- & -- & .42 & -- & -- \\
\hline Neuroticism & -- & -- & .96 & -- & -- \\
\hline Extroversion & -- & .83 & -- & -- & -- \\
\hline Psychoticism & -- & -- & -- & -- & .60 \\
\hline EPQ Lie Scale & -- & -- & -- & -- & -.65 \\
\hline
\end{tabular}


Table 2: Item loadings for a two-factor solution for the SPQ.

\begin{tabular}{|l|c|c|}
\hline \multirow{2}{*}{\multicolumn{1}{|c|}{ SPQ subscales }} & \multicolumn{2}{c|}{ Factor Loadings } \\
\cline { 2 - 3 } & SPQ Factor 1 & SPQ Factor 2 \\
\hline Ideas of Reference & .73 & -- \\
\hline Odd Beliefs/Magical Thinking & .64 & -- \\
\hline Unusual Perceptual Experiences & .80 & -- \\
\hline Odd Thinking and Speech & .55 & -- \\
\hline Suspiciousness/Paranoid Ideation & .52 & -- \\
\hline Inappropriate/Constricted Affect & -- & -.74 \\
\hline Odd/Eccentric/Peculiar Behaviour & .49 & -- \\
\hline Lack of Close Friends & -- & .90 \\
\hline Excessive Social Anxiety & -- & .52 \\
\hline
\end{tabular}


Table 3: Item loadings for a three-factor solution for the SPQ.

\begin{tabular}{|l|c|c|c|}
\hline \multirow{2}{*}{\multicolumn{1}{|c|}{ SPQ subscales }} & \multicolumn{3}{c|}{ Factor Loadings } \\
\cline { 2 - 4 } & SPQ Factor 1 & SPQ Factor 2 & SPQ Factor 3 \\
\hline Ideas of Reference & -- & .78 & -- \\
\hline Odd Beliefs/Magical Thinking & .59 & -- & -- \\
\hline Unusual Perceptual Experiences & .98 & -- & -- \\
\hline Odd Thinking and Speech & -- & .51 & -- \\
\hline Suspiciousness/Paranoid Ideation & -- & .85 & -- \\
\hline Inappropriate/Constricted Affect & -- & -- & -.74 \\
\hline Odd/Eccentric/Peculiar Behaviour & -- & .43 & -- \\
\hline Lack of Close Friends & -- & -- & .90 \\
\hline Excessive Social Anxiety & -- & -- & .52 \\
\hline
\end{tabular}


Table 4: Item loadings for a four-factor solution for the SPQ.

\begin{tabular}{|l|c|c|c|c|}
\hline \multirow{2}{*}{\multicolumn{1}{c|}{ SPQ subscales }} & \multicolumn{4}{c|}{ Factor Loadings } \\
\cline { 2 - 5 } & $\begin{array}{c}\text { SPQ Factor } \\
1\end{array}$ & $\begin{array}{c}\text { SPQ Factor } \\
2\end{array}$ & $\begin{array}{c}\text { SPQ Factor } \\
3\end{array}$ & $\begin{array}{c}\text { SPQ Factor } \\
4\end{array}$ \\
\hline Ideas of Reference & -- & .77 & -- & -- \\
\hline Odd Beliefs/Magical Thinking & .59 & -- & -- & -- \\
\hline Unusual Perceptual Experiences & .98 & -- & -- & -- \\
\hline Odd Thinking and Speech & -- & -- & .60 & -- \\
\hline Suspiciousness/Paranoid Ideation & -- & .55 & -- & -- \\
\hline Inappropriate/Constricted Affect & -- & -- & -- & -.74 \\
\hline Odd/Eccentric/Peculiar Behaviour & -- & -- & .76 & -- \\
\hline Lack of Close Friends & -- & -- & -- & .90 \\
\hline Excessive Social Anxiety & -- & -- & -- & .52 \\
\hline
\end{tabular}

